\title{
TERRITÓRIO E TERRITORIALIDADES EM DISPUTA: DA SUBORDINAÇÃO AO CAPITAL AO SISTEMA ALIMENTAR CAMPONÊS
}

\author{
Camila Ferracini Origuéla \\ Universidade Estadual Paulista (UNESP), Instituto de Políticas Públicas e Relações Internacionais \\ (IPPRI) \\ camila.ferracini@unesp.br
}

\begin{abstract}
RESUMO
Em um contexto em que o sistema alimentar capitalista controla a produção, a distribuição e o consumo de alimentos em escala global, analisar as resistências construídas pelos camponeses, assim como a importância do território e das territorialidades nesses processos, se torna cada vez mais necessário. O objetivo desse artigo é analisar experiências de produção, industrialização e comercialização de alimentos tanto convencional como agroecológico em assentamentos rurais no Rio Grande do Sul. Os procedimentos metodológicos consistiram, além da revisão da literatura, em entrevistas semi-estruturadas com camponeses assentados, membros da coordenação e cooperativas do Movimento dos Trabalhadores Rurais Sem Terra (MST) e membros de instituições estatais. Concluiu-se que os camponeses se reproduzem em diferentes condições, produzindo territorialidades que podem ser subordinadas e/ou autônomas. Ademais, nos casos em que os camponeses constroem territorialidades autônomas temos os alicerces de um sistema alimentar camponês. Nesse sistema, os camponeses, em aliança com os consumidores, determinam através de cooperativas, coletivos e grupos gestores a produção, a industrialização e a comercialização de alimentos agroecológicos.
\end{abstract}

Palavras-chave: Paradigma da Questão Agrária. Disputa territorial. Assentamentos rurais. Campesinato autonomia.

\section{TERRITORY AND TERRITORIALITIES IN DISPUTE: FROM SUBORDINATION TO THE CAPITAL TO THE PEASANT FOOD SYSTEM}

\begin{abstract}
In a context of globalization in which the capitalist food system controls the production, distribution, and consumption of food, understanding the resistance produced by peasants is becoming increasingly necessary. Besides the importance of the territory in this process. Based on this, the present article aims to analyze the production, industrialization and commercialization of conventional and agroecological food in the rural settlements in the Rio Grande do Sul. The methodological procedures consisted of documentary research, data collection and systematization and semi-structured interviews. It was concluded that peasants reproduce in different conditions, producing territorialities that can be subordinate and/or autonomous. In cases where the degree of autonomy is high, the basis of a peasant food system is found. This can be characterized as a system in which the processes of production, distribution and consumption of food are controlled by peasants in alliance with consumers. The system is developed from cooperatives, management groups, families groups, that is, different forms of economic and social organization of the peasantry.
\end{abstract}

Keywords: Territory. Territorialities in dispute. Subordination. Autonomy. Peasant food system.

\section{INTRODUÇÃO}

Em um contexto de globalização, o alimento não pode ser compreendido a partir do isolamento de uma das atividades que fazem parte do seu processo produtivo, seja ela a produção, a distribuição ou o consumo. Isso porque as relações e os processos que conectam essas atividades no espaço-tempo são complexos, configurando o que na contemporaneidade pode ser chamado de sistema alimentar capitalista. Esse, por sua vez, é resultado de processos histórico-geográficos que tiveram início no século XVI (McMICHAEL, 2016). À medida que novos agentes e atividades surgiram, o sistema alimentar

\begin{tabular}{|c|c|c|c|}
\hline Caminhos de Geografia & Uberlândia & v. 21, n. 73 & Mar/2020 \\
\hline
\end{tabular}


capitalista se tornou ainda mais dinâmico e, consequentemente, complexo, resultando no distanciamento da agricultura dos ecossistemas locais, na desconexão entre a produção e o consumo de alimentos e na padronização dos hábitos alimentares (GUZMAN, 2012).

Dentre os agentes que compõe o sistema alimentar capitalista, aqueles que possuem maior poder de decisão são as corporações e as redes varejistas. Isso porque elas controlam os nós mais importantes do sistema alimentar na produção, na distribuição e no consumo de alimentos. Segundo Hendrickson et al. (2008), o sistema alimentar possui oito nós de poder, que são: a) a governança; b) o acesso a mercados; c) a propriedade intelectual; d) o acesso a capital; e) a logística; f) o trabalho; g) o marketing; h) as políticas públicas. Poder é a capacidade de uma organização controlar os recursos que the são necessários, mas que também são necessários a outras organizações (TAYLOR e TRHIFT, 1982). O poder também reside na capacidade de articular escalas, de intervir de maneira transescalar (VAINER, 2001).

O poder produz o controle tanto na produção como na circulação de alimentos. É o que Oliveira (1991) denomina de monopólio na produção, subordinando a circulação à produção, e monopólio na circulação, subordinando a produção à circulação. No primeiro caso o capital territorializa-se, culminando na territorialização do capital monopolista na agricultura, e, no segundo caso, o capital monopoliza o território sem territorializar-se, num processo de monopolização do território pelo capital monopolista.

Ainda que não ocorra a territorialização de corporações na produção agropecuária, elas monopolizam o território e, dessa forma, auferem renda da terra na circulação das mercadorias. Também definem através do seu "pacote tecnológico" como os alimentos devem ser cultivados, determinando as técnicas e os tempos da produção camponesa, ou seja, o uso do território. Esse movimento no espaço-tempo produz territorialidades em disputa, de um lado a capitalista, de outro a camponesa. Embora os camponeses se relacionem com o sistema alimentar capitalista, é uma relação de subordinação que mantém a maior parte deles na pobreza, levando-os ao endividamento e, em alguns casos, à perda de suas terras e, consequentemente, à migração.

Contudo, como a subordinação, dependência e marginalização não são processos lineares, os camponeses resistem de diferentes maneiras. Assim, à medida que os camponeses se relacionam com o sistema alimentar capitalista eles podem construir territorialidades subordinadas e/ou territorialidades autônomas. Isso vai depender de fatores externos à unidade camponesa, como o contexto agrário, o movimento socioterritorial e as políticas públicas; e internos à unidade camponesa, como a técnica, a tecnologia, o trabalho familiar, o capital e o acesso ao mercado a partir de circuitos curtos da produção. Mas não apenas, o autoconsumo, a diversidade produtiva, a preservação ambiental na perspectiva de uma consciência de relação com a natureza e consigo mesmo que não consolide uma ruptura metabólica.

Levando em consideração a ascensão de um sistema alimentar capitalista que controla a produção, a distribuição e o consumo de alimentos, que em alguns momentos subordina os camponeses e em outros os excluem do processo produtivo, quais resistências são construidas por esses sujeitos sociais? E qual a dinâmica territorial dessas resistências? Partindo desses questionamentos, o objetivo desse artigo é analisar experiências de produção, industrialização e comercialização de alimentos tanto convencional como agroecológico em assentamentos rurais do Rio Grande do Sul.

A primeira experiência é a do cultivo de soja na Campanha gaúcha. O Rio Grande do Sul é o terceiro maior produtor de soja do país, depois do Mato Grosso e Paraná. O boom de commodities como a soja se deve, principalmente, ao seu elevado preço no mercado internacional, seguido da demanda chinesa impulsionada pelas mudanças nos hábitos alimentares da população. A territorialização da soja nos assentamentos rurais ocorre por intermédio de parcerias entre camponeses e grandes produtores, que se aproveitam das dificuldades enfrentadas pelos assentados para ratificar contratos.

No que se refere às experiências agroecológicas, estudou-se o caso das hortaliças e do arroz na Região Metropolitana de Porto Alegre (RMPA) ${ }^{1}$. A territorialização das hortaliças agroecológicas ocorreu entre as décadas de 1980 e 1990. Já a territorialização do arroz agroecológico teve início em

\footnotetext{
1 A RMPA é formada por 33 municípios. Em oito deles existem assentamentos rurais, que são: Capela de Santana, Charqueadas, Eldorado do Sul, Guaíba, Montenegro, Nova Santa Rita, São Jerônimo e Viamão. No total são 17 assentamentos rurais e 1.172 famílias assentadas.
}

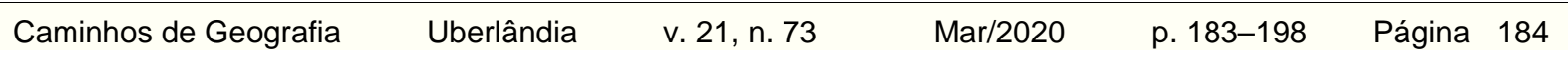


1999, em um contexto de endividamento dos assentados envolvidos na produção de arroz convencional.

O artigo foi estruturado em três partes além dessa introdução e das considerações finais. Na primeira parte, desenvolveram-se as concepções teórico-metodológicas que permitem a análise de três experiências de produção, industrialização e comercialização de alimentos em assentamentos rurais no Rio Grande do Sul. Na segunda parte, abordaram-se os procedimentos metodológicos utilizados na análise das experiências. Por fim, na terceira parte discutiram-se os resultados em três tópicos distintos. $O$ primeiro aborda a relação entre o contexto agrário, o movimento socioterritorial, as políticas públicas e as territorialidades camponesas. O segundo sobre o desenvolvimento de (multi)(pluri)territorialidades na produção de alimentos. E o terceiro analisa a ascensão de um sistema alimentar camponês, que se caracteriza pelo controle camponês na produção, distribuição e consumo de alimentos agroecológicos.

\section{POR UMA TIPOLOGIA DAS TERRITORIALIDADES CAMPONESAS}

No século XIX, o desenvolvimento do modo capitalista de produção na agricultura desencadeou um conjunto de transformações econômicas que alterou a estrutura social do campesinato, resultando em diferentes concepções teórico-metodológicas acerca do seu desaparecimento ou permanência, assim como do seu potencial histórico, reacionário ou revolucionário. Tais discussões deram origem ao que na contemporaneidade é denominado Paradigma da Questão Agrária (PQA) (FERNANDES, 2008). De modo geral, é um paradigma que compreende a questão agrária como um problema estrutural determinado pelo desenvolvimento do modo capitalista de produção na agricultura (FERNANDES et al., 2011).

No âmbito desse paradigma existem duas vertentes, a proletarista e a campesinista. A primeira compreende o desaparecimento do campesinato a partir de duas vias, a da superioridade da grande propriedade, de acordo com Kautsky (1998), e a da desintegração do campesinato, segundo Lênin (1982). A segunda compreende a organização da unidade econômica camponesa (CHAYANOV, 1984), o campesinato como uma classe social (re)criada no bojo do modo capitalista de produção (OLIVEIRA, 1991), o camponês como um modo de se relacionar com a natureza (TOLEDO, 1992) ou como um modo de fazer agricultura (PLOEG, 2008).

Kautsky (1998) e Lênin (1982) abordaram a expansão das relações capitalistas de produção na agricultura na Alemanha e na Rússia, respectivamente. Ambos partiram dos pressupostos teóricometodológicos construídos por Karl Marx e Friedrich Engels. Ao longo da primeira fase de sua vida, Karl Marx estudou a situação dos viticultores de Mosella, e, depois, em 1848, em colaboração com Friedrich Engels, retratou os camponeses nas revoluções na Alemanha e França. Com o fracasso dessas, o referido autor passou a afirmar que o camponês não era uma força revolucionária autônoma. Nesse ínterim, elaborou a concepção de renda da terra absoluta, auferida em virtude do monopólio que uma classe social desempenha sobre a propriedade da terra. Em seu manuscrito A nacionalização da terra de 1872 analisou as relações de propriedade e produção agrícola em uma sociedade revolucionária, opondo-se a qualquer forma de propriedade privada, inclusive a camponesa, defendendo a nacionalização das terras.

Baseando-se nisso, Kautsky (1998) e Lênin (1982) concluíram que a proletarização do campesinato era algo inexorável, imprescindível para o desenvolvimento pleno das forças produtivas e, consequentemente, a emergência do socialismo. Enquanto Kautsky (1998) ressaltou a inferioridade intelectual do campesinato como o principal entrave à melhoria das técnicas de manejo e mecanização agrícola, enaltecendo a superioridade da grande propriedade agrícola; Lênin (1982) constatou que a evolução das técnicas de produção através do uso de máquinas e insumos artificiais resultou em um processo combinado de aburguesamento da parcela mais rica do campesinato e proletarização da parcela mais pobre. Nesse sentido, a transformação capitalista se fundamentava na dinâmica intercamponesa de aprofundamento das relações mercantis, divisão do trabalho e diferenciação de classe. Logo, o desaparecimento do campesinato ocorreria por meio da sua diferenciação social.

De modo geral, em suas análises a respeito do desenvolvimento do capitalismo na agricultura, esses autores levaram em consideração: a) a evolução unilinear da sociedade; b) a sequência histórica dos modos de produção; c) a dissolução do campesinato; e d) a contraposição entre a grande e a pequena exploração agrícola, ressaltando a superioridade da primeira (GUZMÁN e MOLINA, 2005). No que tange as críticas às interpretações apresentadas, destacam-se as seguintes: a) a

$\begin{array}{lllll}\text { Caminhos de Geografia } & \text { Uberlândia } & \text { v. 21, n. } 73 & \text { Mar/2020 } & \text { p. 183-198 Página } 185\end{array}$


incompreensão do contexto histórico da principal obra de Karl Marx, O Capital; b) a interpretação errônea das obras dos últimos dez anos da vida de Karl Marx por Friedrich Engels, que as organizou e publicou; c) a concepção da homogeneização das relações de produção capitalistas e a unilinearidade do processo histórico; e d) a compreensão da agricultura como um ramo da indústria (GUZMÁN e MOLINA, 2005).

No mesmo período em que os marxistas discutiam o destino do campesinato, os naraodiniksrussos e os anarquistas agrários contestaram veementemente suas concepções, numa importante polêmica que se desenrolou de meados do século XIX ao início do século XX. No âmbito dos debates entre os marxistas e os naraodiniks, surge a Escola da Organização da Produção e da Agronomia Social, que produziu um volume de informações sobre o espaço rural da Rússia nunca antes alcançado por qualquer outro país do mundo, da qual fazia parte Alexander Chayanov. A escola contribuiu com a análise da disponibilidade de recursos econômicos e técnicos que tornariam viável uma transformação radical das condições de vida camponesa (ARCHETTI, 2014). Diante disso, o estudo das unidades de produção camponesas exigia a elaboração de categorias que não fizessem parte do repertório oferecido pelos marxistas ou pelos neoclássicos. É a partir de 1911, que Alexander Chayanov passa a se dedicar a edificação de uma teoria do funcionamento das unidades produtivas baseadas fundamentalmente no trabalho familiar.

Para Chayanov (1984) os camponeses são produtores de mercadorias, mas não são capitalistas. O camponês que gere a sua própria unidade de produção obtém como resultado do trabalho de um ano uma quantidade de produtos que, depois de comercializado no mercado, formam o produto bruto da sua exploração. Deste, desconta-se a soma correspondente aos custos da produção e o restante é a retribuição ao trabalho da família durante o ano. O excedente aparece no consumo familiar de bens e serviços. O produto do trabalho familiar é a única categoria possível de rendimento para uma exploração camponesa baseada no trabalho da família. Se o fenômeno social salário não existe na exploração familiar, também não existe o fenômeno social do lucro líquido. Nesse caso é, portanto, impossível aplicar o cálculo capitalista do lucro. O produto indivisível do trabalho camponês não é o mesmo para todas as unidades de exploração familiar, pois dependem da situação do mercado, da localização da exploração em relação ao mercado, as disponibilidades em matéria de fatores de produção, a dimensão e a composição da família e a qualidade do solo.

O trabalho camponês persegue como fim a satisfação das necessidades da família ou, em outras palavras, a reprodução da família e não a obtenção de uma taxa média de lucro. A importância do produto do trabalho do camponês é determinada pela dimensão e composição da família, ou seja, pelo número de membros da família capazes de trabalhar pela produtividade da exploração e pelo grau de autoexploração. A base teórica construída por Chayanov (1984) permitia a contestação da teoria da diferenciação social de Lênin (1982), propondo em seu lugar a teoria da diferenciação demográfica. Enquanto este classifica os camponeses em ricos, médios e pobres, utilizando como critério a compra e a venda da força de trabalho, aquele se baseia no tamanho da família.

Os debates do século XIX sobre o destino do campesinato adquiriram novo impulso nos anos $1960 \mathrm{e}$ 1970. Surge, nesse contexto, o narodnismo marxista, como resultado da virada narodnista que ocorreu no pensamento de Karl Marx em seus últimos dez anos de vida, o denominado "Marx tardio" (1871-1883). Em virtude das discussões elaboradas na Rússia a respeito da obra O Capital, Karl Marx aprendeu a língua do país e passou a dialogar com as interpretações dos narodnistas russos sobre o papel do campesinato no processo histórico (GUZMÁN e MOLINA, 2005). Nesse período, Karl Marx parece concordar com um evolucionismo multilinear dos modos de produção, assim como com a coexistência de diferentes formas de exploração na sociedade (SHANIN, 2005). Ao considerar a diversidade de vias para se alcançar o socialismo, Karl Marx pondera, inclusive, a possibilidade de uma via camponesa.

Teodor Shanin ao estudar o campesinato nas obras de Kautsky (1998), Lênin (1982) e Chayanov (1984) e resgatar as interpretações do "Marx tardio" rompe com a perspectiva unilinear recuperando a multilinearidade na interpretação dos países periféricos (GUZMÁN e MOLINA, 2005). Em seus trabalhos, Shanin (; 2005; 2008) enfatiza que não podemos compreender como funcionam as unidades de produção camponesa sem levar em consideração a estrutura societária em que operam. A história do campesinato se relaciona com as histórias das sociedades mais amplas, não como simples reflexo, mas sim com importante autonomia. Todavia, os camponeses apresentam características sociais e econômicas que se manifestam em qualquer sociedade em que atuem. Desse modo, os camponeses devem ser analisados tanto enquanto tais, as suas especificidades, reações e interações, como no bojo das estruturas societais em que vivem.

\begin{tabular}{|c|c|}
\hline $\mathrm{Ca}$ & Uberlândia $\quad$ v. 21, n. 73 \\
\hline
\end{tabular}


Na década de 1980, com os debates sobre os mecanismos de resistência do campesinato no modo capitalista de produção, surge o marxismo (neo)chayanoviano nos trabalhos de Harriet Friedmann e Jan Douwe Van der Ploeg. Esse último é o principal pesquisador da escola neochayanoviana da Wageningen University (GUZMÁN e MOLINA, 2005). Uma das contribuições da Harriet Friedmann é a caracterização do campesinato, predominantemente nos países capitalistas avançados, a partir da concepção de forma de produção simples de mercadorias. Para a autora, essa é a condição de reprodução de pequenos agricultores no processo histórico. É a maneira que eles se inserem nas formações sociais nas quais se encontram. Por sua vez, Jan Dowe Van der Ploeg busca, por intermédio do conceito style of farming, definir a natureza da agricultura camponesa, analisando o tipo de tecnologia utilizada no manejo dos recursos naturais e o seu grau de implicação no mercado. Com isso, é possível medir o grau de mercantilização das explorações familiares na elaboração de métodos de desenvolvimento local.

Nas décadas de 1970 e 1980, no bojo das críticas à Revolução Verde emerge uma espécie de virada ecológica, renovando-se o interesse pelo conhecimento ecológico (TOLEDO, 1992), pela conservação dos recursos bióticos e genéticos do planeta (BRUSH, 1986) e pela importância das populações tradicionais no desenvolvimento de sistemas agrícolas alternativos, ecologicamente relevantes. Essa guinada ocorre em um contexto de crise ecológica, suscitada pelo modelo de desenvolvimento da agricultura e da sociedade em geral. Mais tarde, os trabalhos de Víctor Manuel Toledo, Stephen Gliessman e Miguel Altieri fundamentaram teórica e metodologicamente o que se conhece por agroecologia.

Recentemente, Ploeg (2016) atualizou as concepções de Chayanov sobre o modo camponês de produção. Segundo o autor, a unidade de produção camponesa é regida por equilíbrios, ou tentativas de alcança-lo. Os equilíbrios internos são entre pessoas e natureza, produção e reprodução, recursos internos e externos, autonomia e dependência, escala e intensidade. Os equilíbrios externos são entre cidade e campo, agricultura, processamento e comercialização, Estado e camponês, crescimento agrário e crescimento demográfico. Ao desenvolver o equilíbrio, o camponês busca a melhoria dos rendimentos e, como consequência disso, a reprodução da família na terra.

De acordo com as concepções apresentadas, o camponês pode ser compreendido como modo de produção, classe social ou modo de manejar os recursos naturais. Embora sejam categorias distintas, não precisam ser excludentes entre si. Até porque, para que o modo camponês de fazer agricultura resista, a luta de classes é necessária. Dessa forma, nesse artigo o camponês é compreendido como um modo de viver, de saber, de produzir, de se relacionar com a natureza, mas, também, como uma classe social. Essa se constitui na medida em que os camponeses se organizam e lutam por terra, infraestrutura, crédito, políticas públicas, entre outros.

Cada uma das concepções apresentadas anteriormente contribui de alguma forma com a compreensão do campesinato na contemporaneidade. Dois processos se destacam nesse sentido, a subordinação e a autonomia. A subordinação ocorre por intermédio da renda da terra. Ou seja, é a partir da sujeição da renda da terra que o capital adentra o universo camponês, subordinando-o pela ação dos monopólios. Entretanto, é justamente no seio dessa contradição que os camponeses se organizam enquanto classe social, gestando um movimento contrário a esse processo. O resgate do modo camponês de fazer agricultura, em consonância com a natureza, faz parte dessa organização.

Ao resgatar o seu modo de fazer agricultura, sua relação com a natureza, entre outras resistências, os camponeses estão lutando por maior autonomia na produção de alimentos. A autonomia pode ser compreendida como a desvinculação parcial ou total das forças do capital e do mercado (PLOEG, 2008) ou, ainda, como poder relativo dentro das cadeias de mercadorias (SIMULA, 2015). As lutas por autonomia são complexas e não se restringem à desvinculação das amarras do capital. De acordo com Kay (2009), a autonomia é uma questão relativa e variável de acordo com a conjuntura política e as experiências de cada movimento social. Em outras palavras, a autonomia é assumida de diferentes formas, no discurso e na prática, variando conforme o contexto social, político e econômico (GONZÁLEZ, 2010).

Do ponto de vista territorial, a subordinação e a autonomia são ações, relações e práticas desenvolvidas pelos camponeses no processo de territorialização. A territorialização é a apropriação social de um fragmento do espaço através das relações de poder, produzindo territórios, territorialidades e temporalidades. O território é resultado da construção histórica do e no espaço. É o resultado das relações e do uso do espaço. A territorialidade corresponde aos sistemas de relações entre os homens e entre esses e a natureza (RAFFESTIN, 1993). 
Nos territórios camponeses as territorialidades são sistemas de relações que objetivam a reprodução da vida. Os usos desses territórios são baseados no trabalho familiar, na produção de alimentos, na relação com a natureza, na luta por autonomia, em tentativas de equilibrar diferentes elementos que fazem parte de um modo de viver, saber e produzir que se contrapõe ao capitalista. Contudo, o modo de produção camponês se relaciona com o capitalista. Nesse embate entre diferentes usos dos territórios, novas territorialidades são construídas.

As territorialidades podem mudar conforme os contextos, mas não descaracterizam o território camponês enquanto tal. Ou seja, não faz do camponês menos ou mais camponês, mas permite que esse se encontre em uma condição de subordinação, em uma condição de autonomia, ainda que sempre relativa, ou em uma condição híbrida, a mais comum de ser encontrada na realidade. São territorialidades construídas na medida em que os camponeses se relacionam com a natureza, com o mercado, com os consumidores, com a cidade, com o Estado etc.. Por isso, a condição híbrida, chamada de (pluri)(multi)territorialidades é a mais comum. Ela pode acontecer em tempos diferentes ou ao mesmo tempo.

$\mathrm{Na}$ figura 1 é possível observar que as territorialidades camponesas estão sujeitas a diferentes condições, a subordinação, a autonomia ou a ambas. E isso vai depender das relações construídas no âmbito da unidade de produção camponesa e na sua relação com o contexto em que está inserida.

Figura 1 - Tipologia de Territorialidades Camponesas.

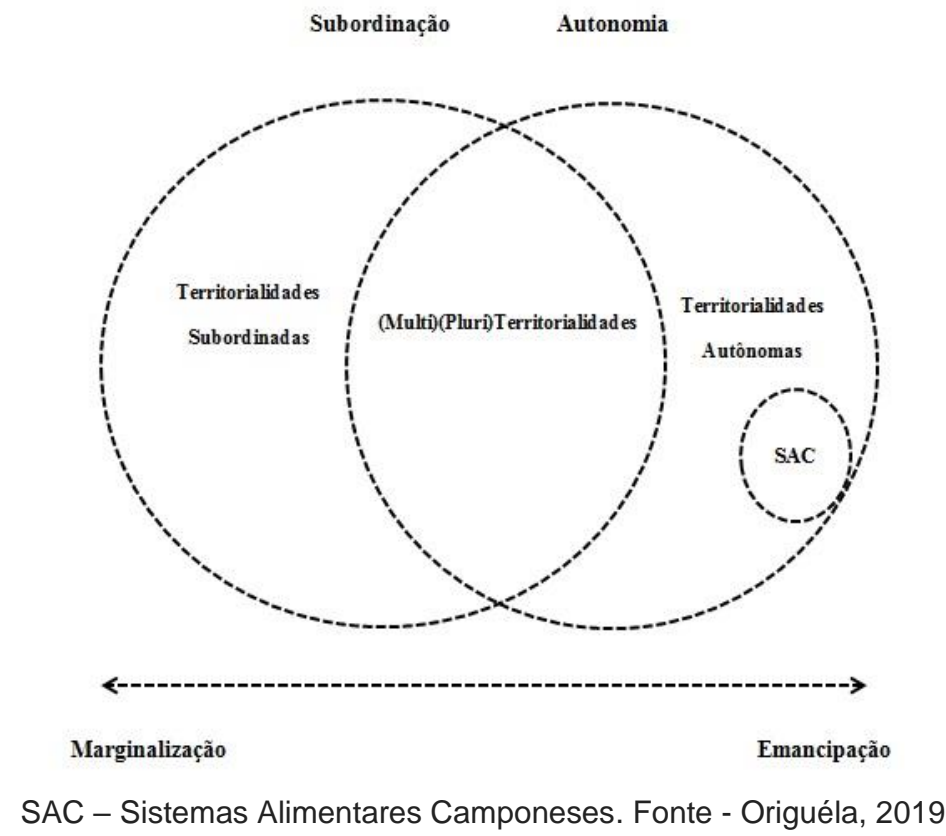

As territorialidades subordinadas são produzidas quando o camponês se afasta da natureza, dos saberes populares, das diferentes formas de cooperação camponesa, aproximando-se, cada vez mais, aos mercados globais de sementes e agrotóxicos, comercializando seus produtos neles. É um camponês altamente dependente do capital industrial, comercial e financeiro. Muitas vezes, para produzir depende de financiamentos, pois os custos da produção são elevados. Quanto mais dependente, maior a probabilidade desse camponês sofrer um processo de marginalização. $O$ que significa ser excluído do sistema. Todavia, isso depende do contexto. Em um momento de crise, baixos preços dos produtos nos mercados, ou adversidades climáticas o camponês pode perder toda a sua produção. E caso esteja com dívidas, pode perder as terras.

Um camponês subordinado é um sujeito vulnerável. Tanto as relações produzidas na unidade de produção como as relações produzidas com o exterior são de dependência, subordinação. Contudo, isso pode ser revertido caso o camponês percorra o caminho oposto.

Por outro lado, as territorialidades autônomas são produzidas quando o camponês se aproxima da natureza, constrói uma base de recursos autocontrolada, baseia-se nos seus saberes populares, 
produz as sementes e os insumos de que necessita, atua em cooperação com outros sujeitos, constrói mercados camponeses populares, aproximando-se dos consumidores.

As territorialidades autônomas protegem os territórios camponeses das instabilidades econômicas e ambientais. Além de preservar as suas características culturais. É uma maneira de defender os territórios conquistados. Não só para aqueles que neles vivem, mas para toda a sociedade que depende dos alimentos produzidos por esses sujeitos. Nesses casos, os sujeitos se organizam coletiva e autonomamente por meio de redes, numa práxis de transformação dos usos dos territórios.

Aos poucos, outros territórios vão sendo transformados. A cooperativa que passou a produzir alimentos agroecológicos, o assentamento rural, começando com um lote aqui, outro ali, alcançando toda a comunidade, o bairro que recebe a feira etc.. As territorialidades autônomas requerem uma práxis libertadora, com base na ação e na reflexão sobre a ação (FREIRE, 2011).

\section{METODOLOGIA}

Entre 1975 e 2015 foram criados 344 assentamentos rurais com 13.810 famílias assentadas no Rio Grande do Sul (DATALUTA, 2017). Até o final dos anos 1980, a criação desses territórios se concentrou nas regiões norte e nordeste do estado. Depois disso, concentraram-se na RMPA e na Campanha gaúcha. De acordo com Dalbianco et al. (2014), a principal atividade agrícola desenvolvida nesses territórios é a produção de grãos, com destaque para a soja, o milho, o feijão e o arroz, seguidos da produção de hortaliças e pomares. Uma parte significativa dos cultivos de arroz e hortaliças é agroecológica. Na safra 2016/2017, 546 famílias assentadas produziram arroz e 158 famílias hortaliças, ambos agroecológicos. Esses dados evidenciam a expansão da agroecologia nos assentamentos rurais no estado, numa tentativa de diminuir a subordinação dos camponeses ao capital. Por outro lado, segundo Dalbianco et al. (2014), 2.998 famílias assentadas produzem soja no estado. O que evidencia, também, a expansão de uma cultura altamente dependente do mercado, ou seja, do capital.

Levando em consideração essas contradições, foram analisadas as experiências de produção de arroz e hortaliças agroecológicos na RMPA e a de soja na Campanha Gaúcha. Ao todo, foram realizadas 28 entrevistas semi-estruturadas com o objetivo de compreender a territorialização dessas culturas nos territórios camponeses, assim como as territorialidades construídas. Foram entrevistados 12 camponeses assentados, nove membros da coordenação e cooperativas do MST, visto que o Movimento é diretamente envolvido na produção de alimentos agroecológicos no estado, além de sete membros de instituições estatais, como do Instituto Nacional de Colonização e Reforma Agrária (INCRA), da Associação Riograndense de Empreendimentos de Assistência Técnica e Extensão Rural (EMATER-RS/Ascar) e da Secretaria de Desenvolvimento Rural, Pesca e Cooperativismo. O número de entrevistas realizadas seguiu os parâmetros de diversificação - entrevistas realizadas com diferentes informantes-chave - e saturação - quando os argumentos presentes nas entrevistas começam a se repetir (CAMARGO e GELIN, 1974 apud MARRE, 1991). Depois de realizadas, as entrevistas semi-estruturadas foram transcritas e analisadas.

\section{O CONTEXTO AGRÁRIO, O MOVIMENTO SOCIOTERRITORIAL E AS POLÍTICAS PÚBLICAS}

Conforme discutido na primeira parte desse artigo, à medida que os camponeses se territorializam, territorialidades são construidas. As territorialidades podem ser subordinadas, autônomas ou ambas, ocorrendo ao mesmo tempo ou em tempos diferentes. Essas territorialidades dependem das relações construídas entre os camponeses e o contexto agrário, entre os camponeses e o movimento socioterritorial e entre os camponeses e o Estado e suas instituições. Em outras palavras, são as relações desenvolvidas entre o camponês e os elementos externos à sua unidade de produção.

Embora sejam externos eles influenciam diretamente na condição de reprodução do campesinato. A começar pelo contexto agrário, que é o de ascensão do sistema alimentar capitalista. No Brasil, o sistema em questão vem se desenvolvendo desde a Revolução Verde. Além de controlar as indústrias a montante e a jusante, esse sistema determina todos os outros processos que envolvem a produção, a distribuição e consumo de alimentos.

Como consequência disso, é um sistema que pode se apropriar diretamente do território, processo denominado de territorialização, ou pode controlar a maneira como o território é usado, as territorialidades. O sistema alimentar capitalista pode definir as territorialidades, controlando as

\begin{tabular}{llllll}
\hline Caminhos de Geografia $\quad$ Uberlândia & v. 21, n. $73 \quad$ Mar/2020 & p. 183-198 & Página 189
\end{tabular}


técnicas utilizadas, as normas produtivas, a utilização de tecnologias, o acesso ao mercado, a disponibilidade de capital e as políticas públicas. O sistema alimentar capitalista não precisa se apropriar dos espaços para controla-los, ele simplesmente define o seu uso, controlando as atividades desenvolvidas nele e a partir dele.

Nesse contexto, os camponeses se reproduzem subordinando-se ao sistema alimentar capitalista ou, ao contrário, lutando por maior autonomia em relação a ele. O contexto agrário produz, portanto, os dois extremos das territorialidades camponesas, a subordinação e a autonomia. $E$ isso acontece porque enquanto alguns camponeses são integrados às cadeias de commodities, outros são excluídos dessas. Aqueles que por diferentes motivos foram excluídos podem reconstruir seus sistemas alimentares de base local ou regional com maior autonomia.

No caso da produção de soja, os camponeses assentados na Campanha gaúcha se encontram em uma região de expansão dessa cultura, logo uma parte será integrada à produção da oleaginosa. Enquanto isso, a produção de arroz agroecológico é desenvolvida por camponeses que foram excluídos da produção de arroz convencional. A exclusão aconteceu em um contexto de crise dos preços da cultura convencional, o que levou vários camponeses ao endividamento.

Nesse contexto os camponeses são, por um lado, subordinados, mas, por outro lado, resistem lutando por maior autonomia. Nos casos estudados, enquanto uma parte dos assentados produz soja, subordinandose aos ditames do sistema alimentar capitalista, outra parte luta por autonomia na produção, industrialização e comercialização de alimentos agroecológicos.

De acordo com Shanin (2008), as respostas construidas pelos camponeses a situações de crise são extremamente complexas. Mais do que isso, esses sujeitos não esperam soluções alheias. Dessa forma, "as soluções encontradas para o problema de como permanecer camponês e assegurar a subsistência da família costumam ser muito flexíveis, inventivas e criativas" (p. 25). Além do contexto agrário, as resistências vão depender de outros dois fatores externos à unidade de produção camponesa, o moimento socioterritorial e as políticas públicas voltadas para a agricultura camponesa.

Os assentamentos rurais são criados quando os camponeses ocupam terras pressionando os governos a desapropriá-las. Nesses processos, a organização desses sujeitos em movimentos socioterritoriais é essencial. O movimento socioterritorial é aquele possui o território como trunfo, ou seja, a sua existência e resistência depende do território (MARTIN e FERNANDES, 2004). Nesse sentido, o movimento socioterritorial é fundamental no acesso a terra, ou seja, na construção de territórios camponeses. Ademais, ele permite que os camponeses assentados continuem na terra através da organização desses sujeitos em associações, cooperativas, grupos gestores, entre outros.

Nos casos estudados, os assentados que produzem soja na Campanha gaúcha participaram dos processos de formação, espacialização e territorialização do MST no estado. Todavia, nos dias atuais não possuem qualquer relação com o Movimento. Ao contrário, muitos não concordam com as propostas político-econômicas do MST. Diferentes desses, os assentados na RMPA participam das cooperativas, dos coletivos e dos grupos gestores. Isso não quer dizer que eles concordam com todas as propostas do Movimento, mas, mesmo assim, participam das diferentes formas de organização social e econômica existentes nos assentamentos rurais, contribuindo com a construção e consolidação desses espaços.

A organização social e econômica dos camponeses assentados é fundamental na construção de territorialidades autônomas. Isso porque, quando o camponês não possui os instrumentos necessários para a produção agropecuária ele pode acessá-los através da associação, da cooperativa ou dos coletivos. No caso do arroz agroecológico, por exemplo, os assentados possuem acesso a sementes, a maquinários, aos locais de secagem e armazenamento por intermédio das cooperativas. Nesses casos, a cooperativa funciona como uma extensão da unidade de produção camponesa.

O último fator é a política pública. E esse fator está relacionado à pressão exercida pelos movimentos socioterritoriais ao Estado na criação e execução de políticas públicas voltadas à agricultura camponesa. O desenvolvimento da produção de alimentos agroecológicos só foi possível devido a algumas políticas públicas.

A primeira é o Programa Nacional de Educação na Reforma Agrária (Pronera) que desde 1998 possibilita a formação de camponeses assentados. A segunda e terceira são o Programa de Aquisição de Alimentos (PAA) e o Programa Nacional de Alimentação Escolas (PNAE), que permitem a comercialização dos alimentos produzidos pelos assentados. A quarta é o Programa Terra Forte, criado em 2009 com o objetivo de implantar ou modernizar empreendimentos agroindustriais em assentamentos rurais. $\mathrm{E}$,

$\begin{array}{lllll}\text { Caminhos de Geografia } & \text { Uberlândia } & \text { v. 21, n. } 73 & \text { Mar/2020 } & \text { p. 183-198 Página } 190\end{array}$


por fim, o Projeto de Qualificação da Infraestrutura Básica e Produtiva dos Assentamentos, com o objetivo de qualificar a infraestrutura, aperfeiçoar e diversificar as atividades agropecuárias, além de valorizar a produção agroecológica, as cadeias produtivas familiares e as cooperativas existentes.

Ascensão de um conjunto de políticas públicas voltadas para a agricultura camponesa, tanto em escala nacional como estadual, é imprescindível no processo de construção de territorialidades autônomas. Nesse sentido, faz-se necessário construir políticas públicas de caráter emancipatório (FERNANDES, 2015). Elas permitem que os camponeses tenham acesso a cursos de formação, maquinários, meios de transporte, agroindústrias e mercados. Ou seja, promovem a autonomia do campesinato, eliminando gradativamente a dependência ao atravessador e ao capital industrial, comercial e financeiro.

Com os instrumentos necessários para a produção agrícola, o transporte dos alimentos e 0 beneficiamento, os camponeses possuem autonomia para decidir o que produzir, como produzir e onde vender os alimentos cultivados em seus territórios. As territorialidades autônomas estão relacionadas, portanto, à capacidade do camponês disputar as políticas publicadas criadas pelo Estado. Essas disputas ocorrem através das ações dos camponeses, com destaque para as manifestações, além do constante diálogo com os governos federal, estadual e municipal.

\section{AS (MULTI)(PLURI)TERRITORIALIDADES CAMPONESAS NA PRODUÇÃO DE ALIMENTOS}

A cultura da soja foi introduzida no Rio Grande do Sul em 1914. Até a década de 1940 a produção era destinada exclusivamente à forragem animal. Depois disso, passou-se a produzir o grão e o farelo. Em 1947 teve início a exportação desses itens para a Europa, transformando a oleaginosa em uma cultura de exportação. Na década de 1950, 90\% dos cultivos se concentravam em três microrregiões do estado: Missões, Santa Rosa e ljuí. No final da década de 1960, a soja alcançou o status de cultura comercial, expandindo-se não só no Rio Grande do Sul, mas nos estados de São Paulo, Mato Grosso do Sul e Minas Gerais.

Nesse período, a soja era cultivada com tecnologia importada dos Estados Unidos ou adaptada de outras culturas, como o trigo. No caso do estado, a expansão ocorreu, sobretudo, no norte e nordeste em pequenas e médias propriedades rurais. Muitos camponeses acabaram perdendo as suas terras nesse contexto. A partir dos anos 2000, com o boom das commodities no país, desencadeado, sobretudo, pela demanda chinesa, ocorreu a territorialização da soja na porção centro-sul do estado, mais conhecida como Campanha gaúcha.

Historicamente, a Campanha gaúcha se destinava à pecuária e, mais recentemente, ao cultivo de arroz. Porém, nos últimos anos, houve a territorialização da produção de soja e de eucalipto. A expansão da soja ocorreu, sobretudo, nas áreas anteriormente destinadas à pecuária. Os sojicultores não possuem a posse da terra nessa região, arrendando o que é necessário para o cultivo. São sujeitos oriundos do norte e nordeste do estado. Eles preferem arrendar as terras, pois assim podem investir o capital na aquisição de sementes, agrotóxicos e maquinários.

Os assentamentos rurais criados na região acabaram sendo inseridos no cultivo da soja. Alguns assentados são oriundos no norte e nordeste do estado e já produziam soja nessas regiões, reproduzindo esse mesmo cultivo na Campanha gaúcha. Ademais, os preços da oleaginosa no mercado internacional são bastante atrativos, motivando os assentados que nunca tiveram contato com a oleaginosa antes a produzirem.

De acordo com Dalbianco et al. (2014), 90\% das famílias assentadas que cultivam soja adquirem as sementes necessárias no mercado, provavelmente, da Monsanto, agora Bayer. No manejo do solo, $95 \%$ das famílias utilizam a adubação química. Ao preparar o solo para o cultivo, $75 \%$ das famílias adotam o plantio direto, sendo o preparo convencional utilizado por cerca de $20 \%$ dos assentados. Já no caso dos agrotóxicos, $90 \%$ das famílias os utilizam no plantio. Pode-se notar que os camponeses são altamente dependentes do mercado, adquirindo nele as sementes, os adubos químicos e agrotóxicos.

$\mathrm{Na}$ colheita da soja, os maquinários utilizados pelos assentados podem ser próprios ou alugados. Além dos altos custos de produção com sementes e agrotóxicos, os camponeses que não possuem maquinários precisam alugá-los. Depois disso, os grãos são vendidos para as cooperativas ou cerealistas existentes no estado, revendendo-os às agroindústrias ou corporações.

Levando-se em consideração o caso dos assentados que produzem soja, pode-se afirmar que existem camponeses altamente e parcialmente subordinados ao sistema alimentar capitalista. Os

$\begin{array}{lllll}\text { Caminhos de Geografia } & \text { Uberlândia } & \text { v. 21, n. 73 } & \text { Mar/2020 } & \text { p. 183-198 Página } 191\end{array}$


altamente subordinados são aqueles que dependem exclusivamente do cultivo de soja. São famílias que produzem somente a oleaginosa ou arrendam parte de suas terras para isso. Elas não produzem alimentos se quer para autoconsumo, adquirindo tudo o que necessita para se reproduzir no mercado. Mas, por outro lado, existem as famílias parcialmente dependentes. Elas produzem leite, hortaliças, entre outros gêneros, para autoconsumo e/ou comercialização. Nesses casos, mesmo altamente dependentes do mercado no cultivo da oleaginosa, possuem certa autonomia nos outros cultivos, sobretudo naqueles voltados para o autoconsumo.

Enquanto no primeiro caso, os camponeses se reproduzem a partir de territorialidades subordinadas, no segundo caso, têm-se (multi)(pluri)territorialidades subordinadas e autônomas. Isso acontece quando os camponeses produzem ao mesmo tempo, ou em tempos diferentes, uma cultura altamente dependente do mercado, como é o caso da soja, mas também produzem outras culturas para autoconsumo ou venda direta aos consumidores, como é o caso das hortaliças.

A subordinação total ou parcial vai depender das necessidades da família, ou seja, das tentativas de se equilibrar os fatores internos e externos à unidade de produção camponesa. Com relação aos fatores internos, um elemento importante é o envelhecimento da família e a migração dos filhos. Quando isso acontece, os assentados não possuem mão-de-obra suficiente em seus lotes. E como a cultura da soja é altamente mecanizada acaba sendo uma alternativa. Ou, até mesmo, o arrendamento de parte do lote para outros assentados ou médios e grandes produtores cultivarem. Ademais, dentre os fatores externos, cabe destacar a territorialização da soja nas regiões onde os assentamentos estão localizados. O que acaba criando toda uma infraestrutura que favorece esse tipo de cultivo.

Contrariando a subordinação total, os assentados da RMPA produzem hortaliças e arroz agroecológicos. A produção de arroz em larga escala foi introduzida no estado no início do século XX. Desde então, uma das características desse cultivo é o arrendamento capitalista de grandes porções de terras, a utilização de meios de produção agrícolas produzidos industrialmente e o predomínio do trabalho assalariado (BESKOW, 1986). A partir da década de 1960, com a modernização da agricultura, alterou-se a base técnica da produção agrícola. No caso do arroz, houve a intensificação dos processos capitalistas de produção, destacando-se o uso cada vez mais intensivo e disseminado de colheitadeiras automotrizes, tratores de maior potência e insumos químicos. Isso resultou na expansão da área plantada, no aumento da produtividade e na diminuição da mão-de-obra empregada. Nesse período, o Rio Grande do Sul era responsável por 25,2\% da produção nacional de arroz, sendo quase dois terços da produção desenvolvida a partir de arrendamentos².

Na década de 1980, devido à diminuição do crédito agrícola disponibilizado pelo Estado, muitos arrendatários faliram. Em decorrência disso, agricultores camponeses oriundos do estado de Santa Catarina se estabeleceram na RMPA, arrendando terras para o cultivo de arroz. Os "catarinas", como eram chamados, eram camponeses que possuíam maquinários e capital, ambos financiados pelos engenhos de arroz catarinenses, daí o nome. Mais tarde, alguns desses "catarinas" se transformaram em médios e grandes produtores de arroz. Concomitantemente à chegada dos "catarinas", os camponeses sem-terra começaram a ocupar propriedades na região, pressionando o Estado na criação de assentamentos rurais.

Os camponeses assentados na RMPA não estavam acostumados a produzir alimentos em áreas de várzea, predominante na região. Aliado a isso, estavam completamente descapitalizados, o que os impedia de investir na produção agropecuária. E os assentamentos rurais careciam de infraestrutura básica, sendo o pouco de recurso que possuíam investidos nas necessidades mais imediatas. Como consequência, os camponeses começaram a arrendar suas terras para os "catarinas" produzirem arroz.

Os assentados se encontravam em uma condição de subordinação. Outros camponeses, ao invés de arrendarem as suas terras, começaram a cultivar arroz por conta própria, organizando-se em cooperativas, como a Cooperativa de Produção Agropecuária de Nova Santa Rita (COOPAN), a Cooperativa de Produção Agropecuária dos Assentados de Charqueadas Ltda (COPAC), a Cooperativa de Produção Agropecuária dos Assentados em Tapes Ltda (COOPAT) e a Cooperativa dos Trabalhadores Assentados da Região de Porto Alegre Ltda (COOTAP). Além de surgirem em virtude dos problemas impostos pelo mercado na produção e comercialização de arroz, essas cooperativas surgiram em um momento de intensas discussões sobre cooperação agrícola nos

\footnotetext{
${ }^{2}$ Op. Cit.
} 
assentamentos rurais. O MST compreendia que a consolidação de cooperativas viabilizaria a produção agropecuária nesses territórios, além da organização política dos camponeses.

Como o cultivo de arroz era convencional, os assentados utilizavam muitos agrotóxicos na lavoura. Vários camponeses atribuíam o adoecimento das famílias, principalmente daqueles diretamente envolvidos nas lavouras, ao uso de insumos químicos. Isso gerava descontentamentos, até porque existiam famílias que produziam hortaliças e não queriam que essas fossem contaminadas com a pulverização aérea. Desde a territorialização dos camponeses nessa porção do estado, o cultivo de hortaliças esteve presente. Os assentados as produziam para autoconsumo, comercializando o excedente. Muitas famílias não usavam agrotóxicos nesses cultivos ou quando isso acontecia era muito pouco, o que facilitou a expansão da agroecologia no decorrer dos anos.

Pode-se dizer que dois fatores foram fundamentais para isso. O primeiro foi a atuação de ONGs voltadas às questões ambientais nos assentamentos rurais. Os assentados eram conscientizados sobre a necessidade de se construir uma agricultura alternativa, cada vez menos dependente do modelo difundido pela Revolução Verde. O segundo, como resultado da atuação dessas ONGs no espaço urbano, foi o surgimento de feiras ecológicas no município de Porto Alegre. As feiras tinham como objetivo o comércio justo de alimentos saudáveis. E deram certo, muitas existem até os dias de hoje.

Em 1998, a produção de arroz entrou em crise levando à falência grande parte dos arrendatários e, consequentemente, dos camponeses. Além disso, ocorreu a insolvência financeira da COOTAP, inadimplente por não pagar os financiamentos adquiridos junto ao Programa de Crédito Especial para a Reforma Agrária (PROCERA) (MARTINS, 2017). Enquanto os camponeses que arrendavam as suas terras perderam os seus aluguéis, os camponeses que produziam arroz estavam completamente endividados (MEDEIROS et al., 2015). Os preços do arroz no mercado caíram, não permitindo o pagando dos custos de produção que eram bastante altos.

É nesse contexto de adoecimento dos assentados, expansão da produção de hortaliças agroecológicas, endividamento e empobrecimento daqueles que produziam arroz, que os camponeses começaram a discutir outras técnicas de produção, dando início ao cultivo de arroz prégerminado sem a utilização de agrotóxicos em 1999.

Com o avanço da produção em alguns assentamentos rurais, em 2002 os camponeses organizaram - Primeiro Seminário do Arroz Ecológico. Nesse evento dialogaram sobre os princípios da agroecologia, apresentando os avanços e desafios. Também definiram que a COOTAP deveria ser reestruturada, atuando na secagem, no armazenamento e na comercialização do arroz. Conforme o cultivo de arroz agroecológico avançava nos assentamentos rurais, os camponeses construíram novas formas de organização, como é o caso do Grupo Gestor do Arroz Ecológico, criado em 2004, no Terceiro Seminário do Arroz Ecológico. Nesse evento os camponeses decidiram que era necessário motivar outras famílias a produzirem agroecologicamente, além de construir autonomia em todo o processo produtivo, dominando das sementes aos mercados.

Pode-se notar que pelas suas experiências, os próprios assentados chegaram à conclusão de que era necessário ter autonomia não só na produção, na unidade camponesa, mas em todo o processo produtivo. Diante dos contextos enfrentados e da própria práxis a autonomia se tornou um objetivo a ser cumprido. Os primeiros passos foram alugar as máquinas e os instrumentos necessários, como a colheitadeira e o secador. Depois disso, a certificação se tornou fundamental, pois até então o arroz agroecológico era comercializado como convencional. No caso das hortaliças, não existia a preocupação com a certificação, pois nas feiras isso não era obrigatório na década de 1990.

A partir de 2003 a legislação brasileira começou a solicitar a certificação, até porque os compradores dos produtos brasileiros, sobretudo os da Europa, começaram a exigi-la. Assim, a questão da certificação surge como uma necessidade interna, principalmente no caso do arroz, mas, também, passou a ser uma exigência externa, daqueles que adquiriam os produtos. No primeiro momento, a certificadora era externa.

No caso das hortaliças, os assentados tiveram que desenvolver outras formas de certificação, visto que os cultivos possuíam peculiaridades. E isso tornava o processo de certificação bastante complicado. Depois de alterações na legislação dos orgânicos, tornou-se possível a certificação via controle social. Esse tipo de certificação só pode ser utilizado em vendas diretas de alimentos. As compras institucionais realizadas pelo PNAE e PAA se caracterizam como venda direta, visto que a cooperativa dos assentados entrega diretamente aos beneficiários os alimentos. As feiras e cestas agroecológicas também. 
O interessante disso é que os próprios assentados ou os seus filhos, organizados em pares, são os responsáveis pelos procedimentos, verificando se os cultivos estão de acordo com as normas. Isso permite que os camponeses ampliem seus conhecimentos sobre agroecologia, que os filhos dos assentados se envolvam de alguma forma no processo produtivo e que redes entre produtores, entre esses e as cooperativas e outras instituições, como a Ecovida, sejam construídas.

A produção de arroz agroecológico ocorre através das chamadas parcerias. Essa prática ocorre porque nem todas as famílias assentadas podem se dedicar à produção de arroz, e como as áreas de cultivo são coletivas não têm a necessidade de todos se envolverem. Dessa forma, a gestão do banhado onde ocorre a produção é coletiva. Assim, um assentado é responsável pela produção de arroz de um grupo de famílias. O valor pago e todos os outros detalhes são definidos pelos envolvidos antes do plantio.

A parceria se torna uma prática interessante ao se levar em consideração o envelhecimento dos assentados e a falta de mão de obra nos lotes. Por outro lado, embora as decisões sejam tomadas em conjunto, a parceria afasta os camponeses do processo produtivo, da prática agroecológica. Mas isso não quer dizer que esses camponeses não produzam hortaliças, por exemplo. Ás vezes apenas um membro da família se dedica à produção de arroz e os outros trabalham na cidade, desenvolvendo atividades que nada tem a ver com a agricultura. Mas a renda retirada dessas atividades pode contribuir com a produção agrícola no lote, principalmente em momentos de crise, de perda da produção por algum fator climático.

Depois de produzido, o arroz é transportado até as unidades de secagem e armazenamento. Existe uma unidade no assentamento Lanceiros Negro. Essa unidade pertence aos assentados, é gerenciada pelas cooperativas. Ter o controle da secagem aumentou significativamente a autonomia dos assentados. Até isso acontecer, o arroz agroecológico era secado e armazenado junto com o convencional em estruturas alugadas, não podendo ser comercializado enquanto tal.

As hortaliças agroecológicas são comercializadas nas feiras da RMPA, nas cestas agroecológicas e na loja da reforma agrária localizada no mercado público de Porto Alegre. Já o arroz agroecológico é comercializado, sobretudo, através das compras institucionais.

Nos assentamentos rurais em que a produção agroecológica se destaca os camponeses constroem territorialidades autônomas. A autonomia não se resume à unidade de produção. As sementes, por exemplo, são produzidas por um grupo de assentados e depois, através das cooperativas, distribuídas para aqueles que não as produzem. Os maquinários são das cooperativas, para usá-los os camponeses pagam pela hora ou dia que utilizaram. Nesse caso, a base de recursos é coletiva, faz parte de uma rede camponesa. É dos camponeses, dos grupos gestores, das cooperativas.

O coletivo de produção de sementes é formado por aproximadamente 51 famílias assentadas que produzem $75 \%$ das sementes utilizadas no cultivo de arroz. Como o cultivo exige muitos cuidados, somente algumas famílias estão aptas a desenvolver esse trabalho. $O$ coletivo das cooperativas que secam e armazenam a produção é formado pelas cooperativas agropecuárias, além da regional, que se responsabilizam pelo transporte da produção até a unidade de secagem e armazenamento. Por fim, o coletivo de comercialização é formando pelas cooperativas que se responsabilizam pela comercialização do arroz agroecológico.

Pode-se afirmar que a estrutura organizativa do grupo gestor é uma organização em rede dos camponeses e das cooperativas. São diferentes níveis e graus de envolvimento dos assentados. Contudo, ela é fundamental na gestão dos territórios e na construção de territorialidades autônomas, ainda que existam contradições no decorrer desses processos. O modo como os camponeses estão utilizando, gestando, construindo os seus territórios permite que eles tenham certa autonomia em relação aos mercados. Nesse caso, o território possui um caráter emancipatório.

Também existem camponeses altamente e parcialmente autônomos. O primeiro caso ocorre quando o camponês, individual ou coletivamente, possui autonomia na produção de alimentos, não dependendo do mercado para obter sementes e insumos. Em alguns casos, o camponês pode não produzir em sua unidade a semente e os insumos, mas adquiri-los de outros camponeses e/ou de cooperativas, numa relação de troca e/ou comercial. Lembrando que, a associação ou a cooperativa são coordenadas pelos próprios camponeses, sendo esses os responsáveis pelas decisões tomadas.

A agroecologia, além de diminuir a dependência aos mercados, permite maior autonomia no processo produtivo, resultando na construção de usos mais autônomos dos territórios ou territorialidades autônomas. Nesse processo, as territorialidades ultrapassam a unidade de produção camponesa, atingindo outros territórios e sujeitos ou agentes sociais. Em decorrência disso, redes transterritoriais

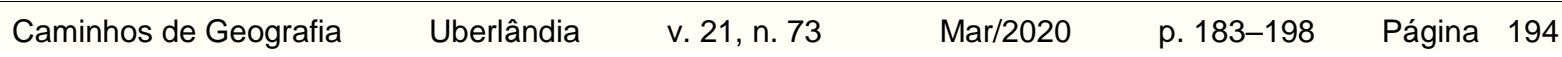


podem ser construidas, como na luta pela soberania alimentar. Essas redes ocorrem, sobretudo, através dos espaços de comercialização de alimentos, os mercados populares camponeses.

Ser altamente autônomo, quando coletivamente, pode produzir um sistema agroalimentar distinto do global, ou em contraposição a esse. Ser parcialmente autônomo significa possuir certa autonomia em um determinado cultivo ou em uma das etapas desse cultivo, mas não no conjunto. Ser parcialmente autônomo é o mesmo que ser parcialmente subordinado. É o meio termo entre a subordinação e a autonomia. É produzir diferentes usos dos territórios, em condições conflitantes de subordinação e autonomia. Entre os polos existem infinitas situações, níveis e graus de subordinação e autonomia.

Um camponês altamente autônomo pode se transformar, a depender do contexto, em um camponês parcialmente autônomo, o que significa parcialmente subordinado. Esse, por sua vez, pode ser transformar em um camponês totalmente subordinado. E tudo isso pode acontecer em um mesmo espaço-tempo. Isso porque os equilíbrios não são apenas entre a unidade de produção camponesa e o contexto em que ela está inserida, mas, também, entre elementos internos, como diminuição da mão-de-obra, doença, envelhecimento dos assentados, entre outros.

As (pluri)(multi)territorialidades camponesas dependem das tentativas de se equilibrar fatores internos e externos à unidade de produção camponesa. Elas explicam as condições de reprodução do campesinato na contemporaneidade. São variações que ocorrem entre os extremos, a subordinação e a autonomia.

\section{O SISTEMA ALIMENTAR CAMPONÊS: OUTRO MODELO DE DESENVOLVIMENTO DA AGRICULTURA A PARTIR DO RIO GRANDE DO SUL}

As (multi)(pluri)territorialidades subordinadas e/ou autônomas são construídas a partir das relações entre os sujeitos e entre esses e a natureza na unidade de produção camponesa e entre essa e o contexto em que está inserida. É o que Ploeg (2016) analisa a partir da concepção de equilíbrios internos e externos. Para entender essas relações, analisaram-se o contexto agrário, o movimento socioterritorial e as políticas públicas. O contexto agrário é o de ascensão do sistema alimentar capitalista, no qual as corporações e as redes varejistas controlam a produção, distribuição e consumo de alimentos. Nesse ínterim, os camponeses podem ser integrados ou excluídos. Os integrados irão se reproduzir em uma condição de subordinação. Já os excluídos podem, a partir de diferentes estratégias, lutar por autonomia. E isso vai depender de outros dois fatores.

A organização dos camponeses, principalmente no movimento socioterritorial, permite que eles atuem na criação de cooperativas, coletivos, grupos gestores, agroindústrias e mercados populares. Ou seja, permite a sua organização enquanto classe social, em oposição ao sistema alimentar capitalista. E essa maneira de se organizar possibilita tanto o acesso a terra como a disputa por políticas públicas. Essas, quando emancipatórias, permitem que os territórios camponeses sejam dotados de infraestrutura e instrumentos necessários à produção de alimentos, fazendo com que esses sujeitos não dependam do sistema alimentar capitalista para ter acesso a eles. Ter poder sobre esses instrumentos é fundamental na construção de territorialidades autônomas.

No que tange a unidade de produção camponesa, os seguintes fatores são fundamentais: a terra, o trabalho, o capital, a técnica e tecnologia e o mercado. Em ambos os casos o acesso a terra é fundamental. O trabalho é familiar, mas pode ser que em determinados períodos do ano a contratação de mão-de-obra ou a venda do trabalho da família seja necessário. O capital é um grande problema aos assentados. Aqueles que produzem soja recorrem a financiamentos, pois os custos de produção são bastante elevados. Aqueles que produzem hortaliças e arroz podem ter acesso aos instrumentos necessários aos cultivos por intermédio das cooperativas.

A técnica e a tecnologia utilizadas na produção de soja são impostas pelo sistema alimentar capitalista. $E$ isso acontece porque os assentados precisam cultivá-la a partir de um determinado tipo de semente, que só responde a determinados tipos de agrotóxicos. Ambos determinados por corporações. No caso dos maquinários utilizados acontece o mesmo. E como grande parte não consegue ter acesso a esses, aluga-os. O que encarece ainda mais a produção. Na comercialização, embora os preços sejam atrativos, muitas vezes não são suficientes para cobrir os custos da produção. Ademais, as cooperativas e as cerealistas compram a oleaginosa dos camponeses no momento em que os preços estão um pouco mais baixos e a armazena, comercializando-a somente quando os preços estão mais elevados.

A técnica e a tecnologia utilizadas na produção de hortaliças e arroz foram desenvolvidas pelos próprios assentados em diálogo com diferentes conhecimentos e instituições sobre agroecologia. No

$\begin{array}{lllll}\text { Caminhos de Geografia } & \text { Uberlândia } & \text { v. 21, n. } 73 & \text { Mar/2020 } & \text { p. 183-198 Página } 195\end{array}$


decorrer desses processos foi elaborado um itinerário técnico com todos os processos que envolvem o cultivo do arroz, desde as sementes até a colheita. É um conhecimento camponês criado de acordo com as necessidades do cultivo e dos assentados. Não são técnicas e tecnologias impostas pelo sistema alimentar capitalista, mas sim construidas coletivamente pelos camponeses no processo de co-evolução com a natureza e de cooperação entre os sujeitos e outras instituições. São saberes e práticas agroecológicas camponesas, adaptadas ao ecossistema local e às necessidades desses sujeitos.

Com a agroecologia, os assentados possuem autonomia na produção de alimentos. Ou seja, não dependem de sementes e insumos produzidos por corporações. Quando não produzem, adquirem dos camponeses que o fazem ou das cooperativas. É assim que uma rede camponesa vai sendo construída. Os saberes, as técnicas, as sementes, os insumos, tudo é compartilhado. Já o acesso ao mercado ocorre via compras institucionais ou através de mercados populares em que os camponeses vendem diretamente seus produtos aos consumidores. Assim, a relação entre os camponeses e os consumidores se torna mais horizontal, num processo de coprodução.

A figura 2 ilustra as (multi)(pluri)territorialidades subordinadas e/ou autônomas do campesinato.

Figura 2 - Graus de subordinação e autonomia do campesinato.

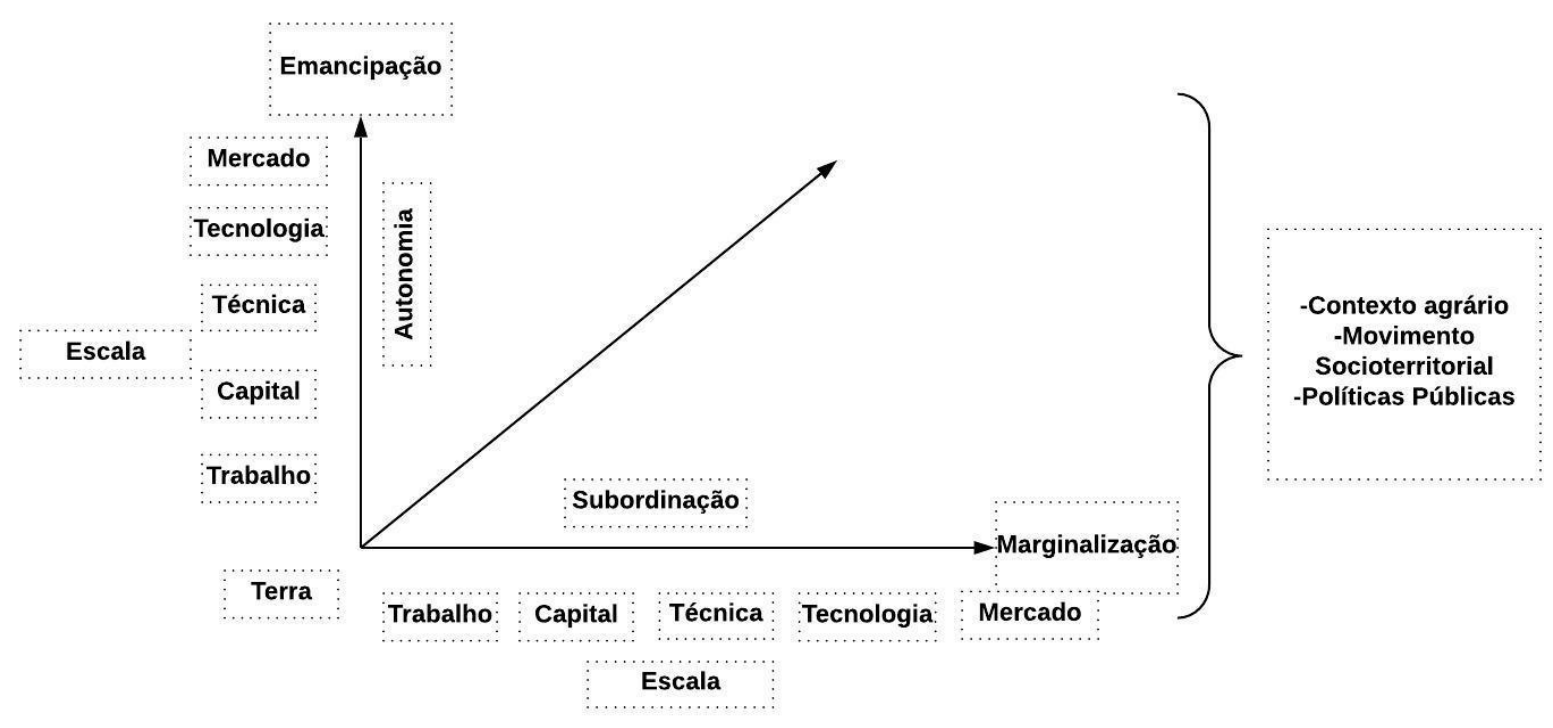

Fonte - Origuéla, 2019.

O mais interessante é que, como a produção de arroz agroecológico é coletiva e em grande escala, pois contempla vários assentamentos rurais, pode-se afirmar que nesse caso existem as bases de um sistema alimentar camponês. Esse, por sua vez, pode ser caracterizado como a produção, distribuição e consumos de alimentos controlados pelos camponeses e em aliança com os consumidores. É um sistema gestado territorialmente a partir de redes formadas por grupos gestores, coletivos, cooperativas, agroindústria e mercados populares. É um sistema agroecológico, que preza pela produção das mudas e sementes, pelo policultivo e por unidades de produção camponesa autônoma.

É um sistema em que o poder de decisão está nas mãos dos camponeses e consumidores. São os primeiros que decidem, por exemplo, como será a organização das safras, das certificações, das cooperativas e agroindústrias. Ou seja, os camponeses estão presentes em todos os espaços construídos no âmbito dos processos citados. Os consumidores participam, sobretudo, dos espaços e redes de comercialização. No sistema alimentar camponês as relações são mais horizontais, aproximando camponês e consumidores, cidade e campo. Para que esse sistema funciona alguns elementos são fundamentais, como a existência de um movimento socioterritorial, como o MST, além das políticas públicas de caráter emancipatório.

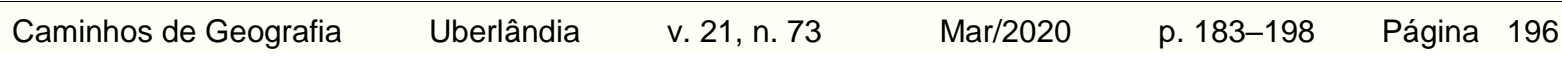




\section{CONSIDERAÇÕES FINAIS}

O sistema alimentar capitalista se apropria dos territórios e/ou determina as territorialidades. Quando o capital determina as práticas e os tempos da agricultura camponesa, apropriando-se do produto do trabalho familiar, têm-se territorialidades subordinadas. Ao contrário, quando os camponeses possuem certo poder, determinando a produção, a industrialização e a comercialização de alimentos agroecológicos, têm-se territorialidades autônomas. Contudo, é possível encontrar ambos os usos em um mesmo território, seja ao mesmo tempo ou em tempos diferentes, mostrando que existem (multi)(pluri) territorialidades camponesas.

As territorialidades autônomas têm como pressuposto outro uso do território, baseados no acesso e controle das técnicas e tecnologias, das sementes, das agroindústrias, dos mercados institucionais e mercados populares. São usos construídos a partir de relações horizontalizadas, de uma práxis transformadora. Essas territorialidades consistem nas bases de outro modelo de desenvolvimento da agricultura ou de outro sistema alimentar, o camponês.

\section{AGRADECIMENTOS}

O presente trabalho foi realizado com apoio da Coordenação de Aperfeiçoamento de Pessoal de Nível Superior (CAPES).

\section{REFERÊNCIAS}

ARCHETTI, E. P. Contextualização histórica do debate sobre a questão agrária na revolução russa. In: CARVALHO, H. M (coord.). Chayanov e o campesinato. São Paulo: Expressão Popular, 2014, p. 15-32.

BESKOW, P. R. O arrendamento capitalista na agricultura: evolução e situação atual da economia do arroz no Rio Grande do Sul. São Paulo: Hucitec, 1986.

BRUSH, S. Genetic diversity and conservation in tradicional farming systems. J. Ethnobiol, Tacoma, n. 1, p. 151-167, 1986.

CHAYANOV, A. La organización de la unidad económica campesina. Buenos Aires: Nueva Visión, 1984.

DALBIANCO, V. P.; CARMO, L. E. A.; MIRANDA, F. Q.; VIGNOLO, A. M.; NEUMANN, P. S. Retrato dos Assentamentos de Reforma Agrária do Rio Grande do Sul. In: VI Simpósio sobre Reforma Agrária e Questões Rurais, 2014, Araraquara, Anais... VI Simpósio sobre Reforma Agrária e Questões Rurais. Araraquara: Suprema Gráfica e Editora, 2014, v. VI.

DATALUTA. Relatório DATALUTA Brasil. [Presidente Prudente: UNESP], 2017. Disponível em: https://drive.google.com/file/d/169emuzewDt9frGJRuvDfWG6jvjxdUMdn/view?usp=drive_open.

Acesso em: 26 fev. 2019.

FERNANDES, B. M. Entrando nos territórios do Território. In: PAULINO, E. T.; FABRINI, J. E (coord.). Campesinato e territórios em disputa. São Paulo: Expressão Popular, 2008, p. 273-302.

FERNANDES, B. M. Políticas públicas e questão agrária: bases para o desenvolvimento territorial camponês. In: RAMOS FILHO, E. et al. (coord.) Estado, Políticas Públicas e Território. São Paulo, Outras Expressões, 2015, p. 17-38.

FERNANDES, B. M.; WELCH, C. A.; GONÇALVES, E. C. Os usos da terra no Brasil. São Paulo: Cultura Acadêmica, 2014.

FREIRE, P. Pedagogia da autonomia: saberes necessários à prática educativa. São Paulo: Paz e Terra, 2011.

GONZÁLEZ, M. Autonomías territoriales indígenas y regímenes autonómicos (desde el Estado) em América Latina. In: GONZÁLEZ, M.; BURGUETE, A. C. M.; ORTIZ, P. (coord.) Autonomia a Debate: autogobierno indígena y Estado plurinacional en América. Quito: Flacso, 2010.

GUZMÁN, E. S. Canales cortos de comercialización alimentaria em Andalucía. Sevilla: Fundación Pública Andaluza Centro de Estudios Andaluces, 2012.

GUZMÁN, E. S.; MOLINA, M. G. de. Sobre a evolução do conceito de campesinato. 3. ed. São Paulo: Expressão Popular, 2005. 
HENDRICKSON, M. et al. The global food system and nodes of power. SSRN Eletronic Journal, Rochester, 2008, p. 1-58. https://doi.org/10.2139/ssrn.1337273

KAUTSKY, K. A questão agrária. Brasília: Linha Gráfica Editora, 1998.

KAY, C. Development strategies and rural development: exploring synergies, eradicating poverty. Journal of Peasants Studies. The Hague, v. 36, p. 103-137, 2009. https://doi.org/10.1080/03066150902820339

LÊNIN, V. O desenvolvimento do capitalismo na Rússia. São Paulo: Abril Cultural, 1982.

MARRE, J. A. L. A construção do objeto científico na investigação empírica. In: Seminário de Pesquisa do Oeste do Paraná, 1991, Cascavel: UNIOESTE, 1991, p. 9-32.

MARTIN, J.; FERNANDES, B. M. Movimento socioterritorial e "globalização": algumas reflexões a partir do caso do MST. Lutas Sociais, São Paulo, v.11/12, p. 1-12, 2004.

MARTINS, A. F. G. A produção ecológica do arroz nos assentamentos da região metropolitana de Porto Alegre: territórios de resistência ativa e emancipação. 2017. Tese (Doutorado em Geografia) - Instituto de Geociências, Universidade Federal do Rio Grande do Sul, Porto Alegre, 2017.

McMICHAEL, P. Regimes alimentares e questões agrárias. São Paulo; Porto Alegre: Editora Unesp; Editora UFRGS, 2016.

MEDEIROS, R. M. V.; LINDNER, M.; MUNHOZ, T. F. Movimentos socioterritoriais e agricultura sustentável: o arroz ecológico na região metropolitana de Porto Alegre - RS. Boletim DATALUTA, Presidente Prudente, n. 92, p. 2-6, 2015.

OLIVEIRA, A. U. A agricultura camponesa no Brasil. São Paulo: Contexto, 1991.

ORIGUÉLA, C. F. Território e territorialidades em disputa: subordinação, autonomia e emancipação do campesinato em assentamentos rurais no Rio Grande do Sul. 2019. Tese (Doutorado em Geografia) - Faculdade de Ciências e Tecnologia, Universidade Estadual Paulista, 2019.

PLOEG, J. D. V. D.. The new peasantries: struggles for autonomy and sustainability in an era of empire and globalization. Londres: Earthscan, 2008.

Camponeses e a arte da agricultura: um manifesto Chayanoviano. São Paulo; Porto Alegre: Editora Unesp; Editora UFRGS, 2016.

RAFFESTIN, C. Por uma geografia do poder. São Paulo: Ática, 1993.

SHANIN, T. A definição de camponês: conceituação e desconceituação. O velho e o novo em uma discussão marxista. Revista NERA, Presidente Prudente, n. 7, p. 1-21, 2005.

Lições camponesas. In: PAULINO, E. T.; FABRINI, J. E. (coord.) Campesinato e territórios em disputa. São Paulo: Expressão Popular, 2008. p. 23-48.

SIMULA, G. Milking Money: exploring the struggle for autonomy from theory to practice. 2015. Paper (Master of arts in development studies). International Institute of Social Studies, The Hague, 2015.

TAYLOR, M. J.; THRIFT, N. J. Industrial linkage and the segmented economy: some theoretical problems. Environment and planning A. Austrália, v. 14, p. 1601-1613,1982. https://doi.org/10.1068/a141601

TOLEDO, V. M. La racionalidad ecologica de la produccion campesina. In: GUZMÁN, E. S.; MOLINA, M. G. (coord.) Ecologia, campesinado e historia. Madrid: Las Ediciones de la Piquet, 1992.

VAINER, C. B. As escalas do poder e o poder das escalas: o que pode o poder local? Cadernos IPPUR. Rio de Janeiro, n. 2, p. 13-32, 2001.

Recebido em: 04/04/2019

Aceito para publicação em: 16/01/2020 